\title{
Understanding the well-being impact of a computer- supported collaborative learning tool: the case of PyramidApp
}

\author{
Eyad Hakami ${ }^{[0000-0002-9742-105 X]}$, Davinia Hernández-Leo ${ }^{[0000-0003-0548-7455]}$ and Ishari \\ Amarasinghe ${ }^{[0000-0003-2960-4804]}$ \\ ${ }^{1}$ Universitat Pompeu Fabra, Barcelona, Spain \\ eyad.hakami01@estudiant.upf.edu \\ \{davinia.hernandez-leo; ishari.amarasinghe\}@upf.edu
}

\begin{abstract}
The global efforts toward evaluating the impact of the use of datadriven technologies on humans' well-being continue to establish societal guidelines for such systems to remain human-centric, serving humanity's values and safeguarding well-being. In this paper, we apply the first activity of IEEE P7010 recommended practice, a methodology and a set of metrics, to understand the well-being impact of a web-based tool (PyramidApp) that allows teachers to design and deploy Pyramid-pattern based collaborative learning activities in classroom learning scenarios. The tool's creators who are learning technology researchers $(\mathrm{n}=2)$ and a sample of the tool's users and stakeholders who are undergraduate students $(n=11)$, master students $(n=14)$ and instructors $(n=2)$ are engaged in surveys and interviews to investigate the tool's well-being impact by reflecting on well-being indicators distributed to multiple well-being domains. The findings discuss possible impacts of the tool on the well-being domains of life satisfaction, affect, psychological state, community, education, government, human settlement and work. The creators also share views about the extent to which the use of IEEE P7010 increases their awareness of the intended and unintended impacts of their tool on well-being.
\end{abstract}

Keywords: Well-being, Computer-supported collaborative learning, Ethics, Values

\section{Introduction and Background}

Given the rapid emergence of Information and Communication Technologies (ICT) and their increasing adoption by individuals and societies, personal and societal well-being are now inextricably linked with the state of our information environment and the digital technologies that mediate our interaction with it [1]. With the growing role of data analytics and Artificial Intelligence (AI) techniques in this digital space, the global efforts toward evaluating the different impacts of digital technologies continue to establish guidelines and metrics for such systems to remain human-centric, serving humanity's values and safeguarding well-being [e.g., 2, 3]. Well-being refers to what is directly or ultimately good for a person or population, and it is not limited to one dimension, but rather encompasses the full spectrum of personal, social, and environmental 
factors that enhance human life and on which human life depends [2]. The expression "digital well-being" is used to describe the impact of digital technologies on what it means to live a life that is good [1], including intended and unintended, positive and negative impacts on all well-being dimensions.

Computer-Supported Collaborative Learning (CSCL) is an interdisciplinary field of research that aims to investigate how learners engage in collaboration with the help of computers. Some of the well-known examples of CSCL scripts include Pyramid, Jigsaw, Think-Pair-Share (TPS), and Thinking Aloud Pair Problem Solving (TAPPS) [4]. Pyramid scripts integrate activities occurring at multiple social levels. First, learners will study a given problem individually to propose an initial solution. Learners then join in small groups and then increasingly larger groups to discuss their solutions, and to propose a shared solution to the given problem. In this study, a tool called PyramidApp that implements a particularization of the Pyramid pattern has been used to deploy CSCL activities [5]. The tool provides an activity authoring space, a teacher-facing dashboard and an activity enactment space for students. The teacher-facing dashboard not only provided a real-time overview of collaboration but also consisted of different controls, e.g., activity pause-resume, increasing time, and an alerting mechanism that informed critical moments of collaboration to the teachers to support their orchestration actions.

We engage samples of the creators, users and stakeholders of PyramidApp in the first activity of IEEE P7010-2020, a recommended practice to assess the well-being impact of autonomous and intelligent systems [3]. This activity is composed of 1) an internal analysis conducted by the tool's creators where they apply internal analysis techniques (e.g., brainstorming, hypothesizing, utilizing scenarios, etc.) and 2) surveys and interviews with the tools' users and stakeholders, to answer the following question: What are the possible impacts of PyramidApp on learner and teacher well-being?

\section{Method}

IEEE P7010 Well-being Impact Assessment (WIA) is an iterative process that aims at producing a well-being indicators dashboard and using it in the design, development, deployment and continual improvement of data-driven tools in order to help safeguard and improve human well-being [3]. This process consists of five activities: 1) Internal, user, and stakeholder analysis, 2) Well-being indicators dashboard creation, 3) Data collection plan and data collection, 4) Well-being data analysis and use of well-being indicators data, and 5) Iteration. The recommended practice provides a wide range of indicators drawn from well-being instruments already in use (i.e., scientifically valid) to be used to identify impacted well-being areas of a particular data-driven technology on the following domains of well-being: satisfaction with life, affect (feelings), psychological well-being, community, culture, education, economy, environment, government, health, human settlement, and work.

We apply the first activity of this approach with the objective of identifying wellbeing domains and indicators that can reflect possible impacts of PyramidApp on the well-being of its users and stakeholders (i.e., students and teachers). This activity 
consists of three tasks: initial analysis, user engagement, and stakeholder engagement. Task 1 is an internal analysis conducted by the tool's creators and involves forecasting, hypothesizing, projecting and utilizing scenarios to select well-being indicators that can reflect the impact of the tool and be used as principles of design during redesign and improvement processes. In the latter two tasks, user and stakeholder engagement, we seek to test the assumptions arriving from task 1.

\subsection{Participants and Procedures}

The following samples were selected based on convenience sampling, and the interviewed students were selected to represent the different views coming from the survey. Sample 1. Learning technologies researchers $(n=2)$ who have co-created PyramidApp and were presented to 134 well-being indicators distributed to 12 well-being domains in a survey manner allowing them to: 1) identify the system and its goals, users, and stakeholders 2) read the definitions and indicators of each well-being domain, and 3) select well-being indicators allocate them to the impacted party (Table 1). Then they were interviewed individually for 30 munities to reflect on the process.

Sample 2. Master students $(n=14)$ who took part in PyramidApp activities on five occasions. They responded twice to an 11-items Yes/No survey: a) after their last use of the tool immediately, and b) two weeks after their last use of the tool (Table 2). Two of them were interviewed individually for 15 minutes to provide in-depth answers.

Table 1. Well-being indicators selected by Sample 1 (creators)

\begin{tabular}{|c|c|c|c|c|}
\hline \multirow{2}{*}{$\begin{array}{l}\text { Well-being do- } \\
\text { mains }\end{array}$} & \multirow{2}{*}{ Well-being Indicators } & \multicolumn{3}{|c|}{ Impacted party } \\
\hline & & Students & Teachers & Society \\
\hline Life Satisfaction & Satisfaction with life as a whole & $\sqrt{ }$ & $\sqrt{ }$ & \\
\hline \multirow{2}{*}{ Affect } & Calm in a given time period & $\sqrt{ }$ & $\sqrt{ }$ & \\
\hline & Stress level in a given time period & $\sqrt{ }$ & $\sqrt{ }$ & \\
\hline $\begin{array}{c}\text { Psychological } \\
\text { well-being }\end{array}$ & Sense one is capable and good at what they do & $\sqrt{ }$ & $\sqrt{ }$ & \\
\hline \multirow{3}{*}{ Community } & Sense one sees oneself as part of a community & $\sqrt{ }$ & & \\
\hline & $\begin{array}{l}\text { Sense that if one were in trouble, they would } \\
\text { have relatives or friends they can count on to } \\
\text { help them whenever they need them, or not }\end{array}$ & $\sqrt{ }$ & & \\
\hline & Satisfaction with relationships & $\sqrt{ }$ & $\sqrt{ }$ & \\
\hline Education & Access to opportunities to learn & $\sqrt{ }$ & & \\
\hline Government & $\begin{array}{l}\text { Sense there is freedom of assembly, demonstra- } \\
\text { tion, and open public discussion }\end{array}$ & $\sqrt{ }$ & $\sqrt{ }$ & \\
\hline \multirow{4}{*}{$\begin{array}{l}\text { Human settle- } \\
\text { ments }\end{array}$} & $\begin{array}{l}\text { Proportion of youth and adults with information } \\
\text { and communications Technology (ICT) skills }\end{array}$ & $\sqrt{ }$ & $\sqrt{ }$ & $\sqrt{ }$ \\
\hline & $\begin{array}{l}\text { Proportion of population covered by a mobile } \\
\text { network, by technology }\end{array}$ & & & $\sqrt{ }$ \\
\hline & Access to internet at home & & & $\sqrt{ }$ \\
\hline & Having a computer at home & & & $\sqrt{ }$ \\
\hline Work & $\begin{array}{l}\text { Sense that one gets support and help from co- } \\
\text { workers }\end{array}$ & $\sqrt{ }$ & & \\
\hline
\end{tabular}


Sample 3. Undergraduate students $(n=11)$ who took part in PyramidApp activities on five occasions. They responded to a 11-items Yes/No survey two weeks after their last use of the tool (Table 2). Three of them were interviewed to provide in-depth answers. Sample 4. Instructors $(n=2)$ who applied PyramidApp activities on many occasions during the last two years. They were interviewed to discuss how the tool could impact their students' well-being and their own well-being as stakeholders of the tool.

\section{$3 \quad$ Findings}

As shown in (Table 1), PyramidApp's creators found the tool impactful on eight different well-being domains. These assumptions were well-aligned with the responses of the tool's users (i.e., students) on the 11-item survey (Table 2). The tool's stakeholder (i.e., teachers) also reported such an impact through their answers in the individual interviews. Students and teachers agreed that the time restrictions in PyramidApp activities can cause negative feelings like stress and anxiety, although they stated that it can be a positive level of stress that could encourage students to quickly generate ideas and be fully active during the learning process. On another hand, they reported that the positive feelings of satisfaction, capability and sense of belonging can be obtained due to the competences of freedom of discussion and collaboration, where students can seek and get help and support from each other. The students found the tool impactful on their learning too and reported that their knowledge about the topic under discussion were developed during the activity in a constructive way.

Table 2. Responses to the questionnaire by samples 2 and 3 (students)

\begin{tabular}{|c|c|c|c|c|c|c|}
\hline \multirow{2}{*}{ Survey items based on Table 1} & \multicolumn{2}{|c|}{$\begin{array}{c}\text { Sample 2(a) } \\
n=14\end{array}$} & \multicolumn{2}{|c|}{$\begin{array}{c}\text { Sample 2(b) } \\
n=14\end{array}$} & \multicolumn{2}{|c|}{$\begin{array}{c}\text { Sample } 3 \\
\mathrm{n}=11\end{array}$} \\
\hline & Yes & No & Yes & No & Yes & No \\
\hline I'm satisfied with the activity & $86 \%$ & $14 \%$ & $100 \%$ & $0 \%$ & $100 \%$ & $0 \%$ \\
\hline I was calm during the activity & $64 \%$ & $36 \%$ & $79 \%$ & $21 \%$ & $100 \%$ & $0 \%$ \\
\hline I was stressed during the activity & $43 \%$ & $57 \%$ & $21 \%$ & $79 \%$ & $0 \%$ & $100 \%$ \\
\hline $\begin{array}{l}\text { During the activity I felt that I was capable at } \\
\text { what I'm doing }\end{array}$ & $93 \%$ & $7 \%$ & $100 \%$ & $0 \%$ & $91 \%$ & $9 \%$ \\
\hline $\begin{array}{l}\text { During the activity I felt that I'm part of a com- } \\
\text { munity }\end{array}$ & $93 \%$ & $7 \%$ & $86 \%$ & $14 \%$ & $45 \%$ & $55 \%$ \\
\hline $\begin{array}{l}\text { During the activity I felt that I belong to a com- } \\
\text { munity }\end{array}$ & $43 \%$ & $57 \%$ & $64 \%$ & $36 \%$ & $45 \%$ & $55 \%$ \\
\hline $\begin{array}{l}\text { During the activity I sense that if I was in trouble, } \\
\text { I would have friends I can count on to get help } \\
\text { whenever I need them }\end{array}$ & $57 \%$ & $43 \%$ & $64 \%$ & $36 \%$ & $55 \%$ & $45 \%$ \\
\hline $\begin{array}{l}\text { I'm satisfied with relationships I had with class- } \\
\text { mates and teacher during the activity }\end{array}$ & $93 \%$ & $7 \%$ & $86 \%$ & $14 \%$ & $73 \%$ & $27 \%$ \\
\hline $\begin{array}{l}\text { Activity has given me access to learning opportu- } \\
\text { nities }\end{array}$ & $100 \%$ & $0 \%$ & $86 \%$ & $14 \%$ & $82 \%$ & $16 \%$ \\
\hline Activity helped to improve my ICT skills & $64 \%$ & $36 \%$ & $43 \%$ & $57 \%$ & $91 \%$ & $9 \%$ \\
\hline $\begin{array}{l}\text { I think the activity has a freedom of assembly, } \\
\text { demonstration, and open public discussion }\end{array}$ & $86 \%$ & $14 \%$ & $93 \%$ & $7 \%$ & $100 \%$ & $0 \%$ \\
\hline
\end{tabular}




\section{Discussion and Future Work}

The application of IEEEP7010 standard was considered by the creators of PyramidApp a good start-point toward including the different dimensions of well-being as additional requirements for the tool's evaluation and redesign processes. They found the wellbeing definitions and indicators provided by this standard rich and informative and that this activity has increased their awareness of the potential well-being impact of their tool and therefore their capacity to address them in the design lifecycle. Samples of the tool's users and stakeholders had views that were to a considerable extent well-aligned with the creators' ones regarding both positive and negative well-being impacts.

The continuation of this work includes identifying data sources to detect well-being issues to be used in creating a well-being dashboard that should be designed and continuously refined in a fashion where data over time is integrated to provide useful, timely and relevant well-being data based on the indicators selected in this phase. Such for monitoring, management and improvement of the tool to help safeguard well-being.

Yet, this approach can be restricted by practical challenges and faced by philosophical arguments that find it difficult to avoid negative impacts through better design of technology and urge to direct these efforts toward training users on healthy and positive use of technology. On the practical level, questions need to be addressed before moving forward include: What data sources are useful to measure students' senses of satisfaction, stress, capability and belonging in a computer-supported collaborative learning environment?

Acknowledgement. This work has been partially funded by the EU Regional Development Fund and the National Research Agency of the Spanish Ministry of Science and Innovation under project grants TIN2017-85179-C3-3-R, PID2020-112584RB-C33. D. Hernández-Leo (Serra Húnter) acknowledges the support by ICREA under the ICREA Academia program. E. Hakami acknowledges the grant by Jazan University, Saudi Arabia.

\section{References}

1. Burr, C., Taddeo, M., Floridi, L.: The Ethics of Digital Well-Being: A Thematic Review. Sci. Eng. Ethics, vol. 26, pp. 2313-2343 (2020). https://doi.org/10.1007/s11948-020-00175

2. IEEE Global Initiative on Ethics of Autonomous and Intelligent Systems: Ethically Aligned Design: A Vision for Prioritizing Human Well-being with Autonomous and Intelligent Systems, First Edition. IEEE. (2019).

3. IEEE.: IEEE Recommended Practice for Assessing the Impact of Autonomous and Intelligent Systems on Human Well-Being. IEEE Std 7010-2020, pp.1-96. (2020). doi:10.1109/IEEESTD.2020.9084219

4. Hernández-Leo, D., Villasclaras-Fernandez, E. D., et al. CSCL scripting patterns: Hierarchical relationships and applicability. In: Proc. of the 6th IEEE Int. Conf. on Advanced Learning Technologies, pp. 388-392. (2006). https://doi.org/10.1109/ICALT.2006.1652452

5. Manathunga, K., Hernández-Leo, D.: Authoring and enactment of mobile pyramid-based collaborative learning activities. Brit. J. of Educational Technology, 49(2), 262-275 (2018). 